\title{
Militância profissional de enfermeiras no campo da formação em Enfermagem: versōes e interpretaçōes do Jornalismo
}

\author{
Professional militancy of nurses in the field of nursing education: versions and interpretations of journalism \\ Militancia profesional de las enfermeras en el campo de la educación en Enfermería: versiones e \\ interpretaciones del Periodismo
}

\author{
Aline Di Carla Laitano ${ }^{1}$ (1) \\ Gilberto Tadeu Reis da Silva² (B) \\ Deybson Borba de Almeida ${ }^{2,3}$ (1) \\ Victor Porfirio Ferreira Almeida Santos ${ }^{1}$ (1) \\ Miller Fontes Brandão ${ }^{1}$ (1) \\ Ridalva Dias Martins ${ }^{2}$ (D)
}

1. Serviço de Atendimento Móvel de Urgência - SAMU 192. Salvador, BA, Brasil.

2. Universidade Federal da Bahia, Programa de Pós-Graduação em Enfermagem e Saúde da Escola de Enfermagem. Salvador, BA, Brasil.

3. Universidade Estadual de Feira de Santana. Feira de Santana, BA, Brasil.

Autor correspondente:

Aline Di Carla Laitano.

E-mail: alinelaitano@yahoo.com.br.

Recebido em 15/02/2021.

Aprovado em 05/07/2021.

DOl:https://doi.org/10.1590/2177-9465-EAN-2020-0356

\section{RESUMO}

Objetivo: analisar as versões e interpretações do Jornalismo sobre a militância profissional de enfermeiras no campo da formação em Enfermagem. Método: estudo histórico, documental, de abordagem qualitativa, embasado na teoria da História Social e com tipificação argumentativa compreensivista. Os dados foram coletados entre setembro e outubro de 2017, em Salvador, Bahia, por meio do levantamento das notícias publicadas no jornal $A$ Tarde, no período de 01/01/1970 a 31/12/1989. Foram identificadas 1.666 reportagens que versavam sobre as enfermeiras e, destas, foram utilizadas 16 reportagens, as quais abordavam a militância profissional no campo da formação em Enfermagem. A análise e a interpretação do material seguiram a proposta da Análise de Conteúdo, na modalidade Temática. Resultados: os achados apontam para a militância profissional das enfermeiras em prol da formação universitária; para a formação técnica, compreendendo o pessoal técnico e auxiliar e para a qualificação profissional, abordando a formação complementar para além do ensino curricular da graduação. Conclusão e implicações para a prática: as publicações evidenciaram o engajamento das enfermeiras contra o ensino universitário descontextualizado e com metodologias ultrapassadas, a luta pela qualificação dos trabalhadores de nível médio e a atuação militante das instituições representativas, que se utilizaram da mídia para comunicar a necessidade de mobilização da categoria em prol do desenvolvimento profissional.

Palavras-chave: Educação em Enfermagem; História; Ativismo Político; Política; Jornalismo.

\section{ABSTRACT}

Objective: to analyze the versions and interpretations of journalism on the professional militancy of nurses in the field of nursing education. Method: a historical and documental study, of qualitative approach, based on the Social History theory and with comprehensive argumentative typification. The data was collected between September and October 2017, in Salvador, Bahia, through a survey of the news published in the newspaper A Tarde, in the period from 01/01/1970 to 31/12/1989. A total of 1,666 reports were identified that dealt with nurses and, of these, 16 reports were used, which dealt with professional militancy in the field of Nursing education. The analysis and interpretation of the material followed the proposal of Content Analysis, in the Thematic modality. Results: the findings point to the nurses' professional militancy in favor of university education; to technical education, including technical and auxiliary staff; and to professional qualification, addressing complementary education beyond the undergraduate curriculum. Conclusion and implications for practice: the publications showed the engagement of nurses against decontextualized university teaching and outdated methodologies, the fight for the qualification of middle-level workers and the militant action of the representative institutions, which used the media to communicate the need for mobilization of the category in favor of professional development.

Keywords: Education, Nursing; History; Political Activism; Politics; Journalism.

\section{RESUMEN}

Objetivo: analizar las versiones e interpretaciones del periodismo sobre la militancia profesional del enfermero en el campo de la formación en Enfermería. Método: estudio histórico, documental, con enfoque cualitativo, basado en la teoría de la Historia Socia y con una tipificación argumentativa integral. Los datos fueron recolectados entre septiembre y octubre de 2017, en Salvador, Bahía, a través de una encuesta de noticias publicadas en Jornal $A$ Tarde, del 01/01/1970 al 31/12/1989. Se identificaron 1.666 informes relacionados con enfermeras y, de estos, se utilizaron 16 informes que abordan la militancia profesional en el campo de la formación en Enfermería. El análisis e interpretación del material siguió la propuesta de Análisis de Contenido, en la modalidad Temática. Resultados: los hallazgos apuntan a la militancia profesional de las enfermeras a favor de la formación universitaria; para la formación técnica, incluido el personal técnico y auxiliar, y para la cualificación profesional, abordando la formación complementaria más allá del plan de estudios de pregrado. Conclusión e implicaciones para la práctica: las publicaciones evidenciaron el compromiso de las enfermeras frente a la educación universitaria descontextualizada y metodologías obsoletas, la lucha por la calificación de los trabajadores de nivel secundario y la acción militante de las instituciones representativas, que utilizaron los medios de comunicación para comunicar la necesidad de movilización de la categoría a favor del desarrollo profesional.

Palabras clave: Educación en Enfermería; Historia; Ativismo Político; Política; Periodismo. 


\section{INTRODUÇÃO}

Apesar dos inúmeros avanços e transformações na área educacional e pedagógica, o modelo de educação em Enfermagem permanece centrado nos moldes tradicionais e hegemônicos, por vezes, atrelado ao paradigma biologicista e tecnicista1. A predominância deste modelo formativo fundamentado na concepção da doença, com foco na cura e fragmentado pela divisão social e técnica do trabalho, resulta de um longo processo histórico que norteou o desenvolvimento da profissão e contribuiu para a fragilidade política das categorias profissionais que integram a equipe de Enfermagem ${ }^{2-4}$.

Além disso, os preceitos educativos assumidos pelas escolas de Enfermagem, no Brasil, seguiram um padrão religioso e militar, pautado no rigor moral e na religiosidade, o que pode ter favorecido uma prática profissional submissa, obediente, abnegada e com caráter devocional. Historicamente, isso pode ter acentuado a fragilidade política da profissão ${ }^{5}$.

Contudo, mais recentemente, algumas práticas de liberdade têm-se relevado capazes de romper com os modos de dominação estabelecidos pelo paradigma hegemônico de formação. Nessa perspectiva, a literatura aponta três possibilidades: possibilidade formativa, visto que o engajamento e o ativismo político são favorecidos por meio de vivências organizativas e de sociabilidade; possibilidade de resistência diante do enfrentamento dos mecanismos de dominação e doutrinamento e práticas de implicação com o mundo, no sentido de estar na luta com o outro e nas ações que objetivem um mundo e uma Enfermagem melhores ${ }^{6}$.

Nesse contexto, entende-se que a militância representa uma possibilidade libertária, pois interfere/sofre interferência na dimensão política da formação presente como dimensão formativa nos projetos político-pedagógicos dos cursos de nível superior, técnico e de qualificação profissional. Dessa forma, ela pode favorecer a revitalização das concepções formativas imbricadas com uma atuação cidadã no cuidado em saúde.

Para este estudo, voltou-se a atenção para as décadas de 1970 e 1980, momento de redemocratização do país, em que as enfermeiras estavam sob a influência de concepções libertárias, democráticas e participativas, lutando contra a imagem desfavorável atribuída a esta categoria e a favor da construção de uma identidade profissional ${ }^{7}$. Além disso, esse período também é marcado pela possibilidade de ruptura com antigos paradigmas que sustentavam a formação em Enfermagem, mais especificamente, neste período, a bandeira de luta da profissão era pela reformulação curricular e em prol da aprovação do currículo mínimo na graduação em Enfermagem ${ }^{8}$.

Na busca pela compreensão de como essa luta profissional foi repercutida para a sociedade, optou-se por utilizar o material jornalístico como fonte de dados por compreender que a mídia é um poderoso instrumento na formação de opinião pública e, portanto, capaz de promover mudanças de comportamento e de conceito. Por seu poder de persuasão, as representações veiculadas na imprensa tendem a ser percebidas e assimiladas como verdades ${ }^{9}$.
Trata-se, assim, do modo da imprensa constituir-se agente da história, sendo recriada uma nova versão, por meio da interpretação manifesta pelo Jornalismo, a partir da maneira como seu olhar se dá sobre a referida realidade ${ }^{10}$, não configurando o fato em si, mas uma aproximação do fato recriado pelo escritor da matéria.

Diante do exposto, este estudo tem como propósito analisar as versões e interpretações do Jornalismo sobre a militância profissional de enfermeiras no campo da formação em Enfermagem.

\section{MÉTODO}

Estudo histórico, de abordagem qualitativa, embasado na teoria da História Social, dimensão do campo histórico e com tipiticação argumentativa compeensivista ${ }^{11}$. A História Social surgiu no contexto da Nova História, movimento iniciado em 1929 com a criação da revista Annales, e substituiu a tradicional narrativa dos fatos por uma história-problema, além de ampliar o interesse para todos os aspectos da vida humana ${ }^{12}$.

A pesquisa voltou-se para o Estado da Bahia, unidade federativa que congrega o maior número de enfermeiras na região Nordeste e quarta no país ${ }^{13}$, o que pode reforçar a expressividade do estudo, tendo em vista a concentração de profissionais nesse Estado. Além disso, é também reconhecida pela expressiva força militante em virtude da atuação política engajada de enfermeiras baianas ${ }^{14-17}$

Foram utilizadas, como fontes de dados para o estudo, as reportagens publicadas no jornal $A$ Tarde, principal meio de comunicação impresso veiculado no Estado da Bahia entre as décadas de 1970 e $1980^{18}$. Nessa época, o jornal tinha como editor-chefe Jorge Calmon Diniz de Bittencourt, importante figura no cenário baiano e nacional. $O$ jornalista e bacharel em Direito foi membro da Academia de Letras da Bahia, diretor da Biblioteca Pública do Estado e participou da implantação do curso de Jornalismo da Universidade Federal da Bahia, em $1949^{19}$ O jornalista atuou também no campo político como deputado estadual, secretário do Interior e Justiça e ministro do Tribunal de Contas do Estado da Bahia.

A escolha da imprensa escrita, como documento histórico para a pesquisa, a fim de analisar a militância das enfermeiras, fundamenta-se na proposta da História Social ${ }^{11}$, campo histórico que tem, como interesse prioritário, os recortes humanos ou das relações humanas.

Os dados foram coletados entre setembro e outubro de 2017 por meio do levantamento de notícias publicadas no jornal $A$ Tarde, disponíveis para acesso on-line a partir de computadores localizados na Biblioteca Pública do Estado da Bahia. As buscas foram feitas em todos os cadernos do jornal publicados no período de 01/01/1970 a 31/12/1989. Foram selecionadas todas as matérias jornalísticas deste período que versavam sobre enfermeiros e enfermeiras, excluindo-se aquelas que tratavam de profissionais de nível médio em Enfermagem ou de outras categorias da área da saúde. Dada a constatação, em coleta experimental, de que as reportagens que abordavam o profissional de nível superior poderiam ser obtidas mediante 
a utilização dos dois referidos termos de busca, optou-se por não realizar buscas com o termo Enfermagem.

Foram identificadas 1.666 reportagens que versavam sobre a categoria, das quais 53 abordavam a atuação militante de enfermeiras em prol da profissão, e, destas, apenas 16 abordavam a militância profissional no campo da formação em Enfermagem.

O processo de análise e interpretação do material coletado seguiu a proposta da Análise de Conteúdo, na modalidade Temática ${ }^{20}$.

Na etapa pré-analítica, realizou-se a leitura flutuante de todo o material e, posteriormente, elaborou-se um breve resumo de cada reportagem, o que contribuiu para a melhor visualização dos dados.

$\mathrm{Na}$ fase de exploração do corpus documental, fez-se a codificação dos dados para determinar as unidades de análise - Unidades de Registro (UR) e Unidades de Contexto (UC). Além disso, as informações foram classificadas e agrupadas em categorias temáticas ${ }^{20}$.

Após a leitura de todo o material, foram obtidas as UR, que são a menor parte do conteúdo e cuja ocorrência guarda relação com as categorias levantadas. Simultaneamente, foram identificadas as UC, parte mais ampla do conteúdo, indispensável para a interpretação do texto, devendo ser tratadas como a unidade básica para a compreensão da codificação da $U^{20}$. As unidades de análise foram organizadas e agrupadas por temática conforme evidenciado nos resultados.

De acordo com as normas e diretrizes estabelecidas pelo Comitê de Ética em Pesquisas com Seres Humanos (CEPSH) e definidas na Resolução no 466/12 do Conselho Nacional de Saúde, houve a dispensa prévia da submissão do projeto de pesquisa ao CEPSH por tratar-se de um estudo de cunho documental e que utilizou apenas documentos públicos e de livre acesso. Além disso, a Resolução no 510/16 estabelece que não serão registradas ou avaliadas pelo sistema CEP/CONEP pesquisas que utilizem informações de acesso público nos termos da Lei no 12.527/2011 e/ou pesquisas que adotem informações de domínio público.

\section{RESULTADOS}

Com base na análise de conteúdo das reportagens publicadas pelo jornal $A$ Tarde, os achados foram agrupados por similaridade temática conforme apresentado no Quadro 1. Os recortes jornalísticos estão apresentados juntamente com o título da matéria e a data de publicação.

Os resultados apontam para a militância profissional das enfermeiras em prol da formação universitária; para a formação técnica, compreendendo o pessoal técnico e auxiliar e para a qualificação profissional, abordando a formação complementar para além do ensino curricular da graduação.

\section{DISCUSSÃO}

Os resultados em destaque no Quadro 1 demonstram que a imprensa deu visibilidade às críticas feitas ao Ensino Superior em
Enfermagem e ao empenho da categoria em operar mudanças no modelo formativo. Segundo estudantes, profissionais e entidades representativas, a formação universitária encontravase desvinculada da realidade, carente de articulação com a comunidade e pautada em uma metodologia ultrapassada O modelo hegemônico de ensino curativista implicou o não favorecimento da formação crítica e emancipada das enfermeiras e pode ter contribuído para perpetuar a subordinação e submissão dessas profissionais a modelos tradicionais e hegemônicos.

Ao corroborar os achados da literatura ${ }^{21}$, na segunda metade da década de 1970, as enfermeiras começaram a questionar alguns princípios básicos que norteavam a sua formação, como o caráter moral e a forte religiosidade até então priorizados em detrimento da competência profissional. Essa tomada de consciência, segundo a autora ${ }^{21}$, pode ter sido motivada pelos movimentos reivindicatórios e lutas sociais pela redemocratização do país, que se descortinavam no contexto histórico do fim da Ditadura Militar e também como resultado de movimentos que ocorriam internamente na categoria, como a busca pela democratização da Associação Brasileira de Enfermagem (ABEn) e a ruptura com a filosofia conservadora da entidade.

Além disso, a aprovação do Parecer nำ271/1962, que definiu o currículo mínimo do curso de Enfermagem, trouxe grande frustração à categoria ao reduzir o curso para três anos, excluir a disciplina de Saúde Coletiva e não definir os objetivos do curso e as disciplinas básicas ${ }^{22}$. Com isso, a ABEn e as Escolas de Enfermagem mobilizaram-se de forma conjunta na tentativa de adequar as disposições curriculares ao novo ideário de formação ${ }^{8}$.

O desafio das enfermeiras era romper com a formação tecnicista em busca de um ensino voltado para a prática reflexiva. Segundo a teoria do ensino reflexivo ${ }^{23}$, a formação deve permitir, ao profissional, a construção do conhecimento com base na interlocução de saberes teóricos e atuação prática, baseado no processo de reflexão-na-ação, ou seja, a capacidade de refletir é estimulada pela interação com as diferentes situações vivenciadas.

A esse respeito, considera-se salutar destacar a postura crítica e engajada das estudantes de Enfermagem que, mesmo inseridas no domínio formativo conservador e biologicista, demonstraram consciência da fragilidade política que permeava as enfermeiras ao caracterizá-las como submissas, inseguras e acomodadas, postura esta que se configurarava como um dos elementos que favoreciam a dominação da categoria, a exploração e a desvalorização profissional. O fato de ter sido reconhecido legalmente como Ensino Superior apenas na década de 1960, mesmo estando o curso de Enfermagem inserido nas universidades, pode ser pontuado como um exemplo da dominação sofrida pelas enfermeiras em prol dos interesses econômicos, dado que a representação ideológica do governo priorizava aumentar o quantitativo de enfermeiras e não a sua qualificação ${ }^{21}$.

Assim, verifica-se que a mídia foi utilizada para comunicar à sociedade sobre os movimentos que ocorriam no âmbito da formação em Enfermagem e sua busca pela reestruturação dos 
Quadro 1. Recortes jornalísticos do jornal A Tarde. Salvador, BA, Brasil (1975 a 1989).

\begin{tabular}{|c|}
\hline Recorte jornalístico \\
\hline Madrigal da UFBA encerra Congresso de Enfermagem \\
\hline $\begin{array}{l}\text { As principais recomendações do Congresso [XXVIII Congresso Brasileiro de Enfermagem], realizado em Salvador, elaboradas na manhã } \\
\text { do dia } 2 \text { passado, dirigem-se, em sua maioria, aos diretores de hospitais universitários, escolas de Enfermagem e à ABEn, sublinhando } \\
\text { a necessidade de currículo que possibilite ao aluno a percepção das características funcionais do exercício profissional. A par desse } \\
\text { aspecto, foi dado destaque ao prejuízo que traz o ensino desvinculado do serviço afetando a parte da assistência à saúde como à da } \\
\text { educação para a profissão. (04.08.1975 - pg 3) }\end{array}$ \\
\hline Valorizar a profissão, meta dos enfermeiros \\
\hline 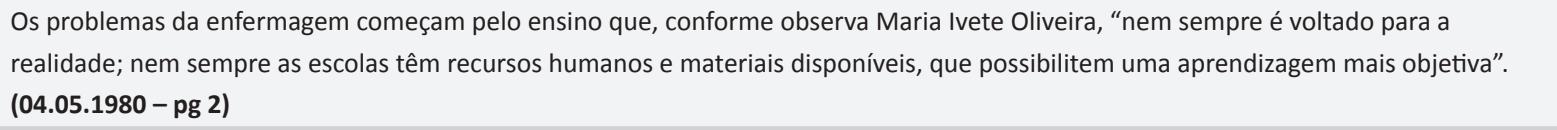 \\
\hline Encontro é encerrado com repúdio e sugestões \\
\hline $\begin{array}{l}\text { Na sessão de encerramento do encontro, realizada à noite no auditório do Instituto de Ciências da Saúde do Estado, foi distribuído um } \\
\text { documento elaborado por } 11 \text { grupos de trabalhos no qual são apresentadas propostas para a reformulação dos currículos dos cursos de } \\
\text { Enfermagem e Obstetrícia. [...] De acordo com as informações da presidenta da Comissão Executiva do II Encontro, durante os três dias } \\
\text { houve debates entre participantes de todo o país, apresentados pela Comissão de Especialistas em Enfermagem do MEC e por um grupo } \\
\text { de professores de vários outros estados brasileiros, a fim de ser elaborada a proposta única com todas as sugestões para a mudança do } \\
\text { currículo. Os principais problemas abordados na proposta dizem respeito à adequação das quatro habilitações profissionais da área, } \\
\text { com atenção especial para a habilitação da enfermeira obstétrica ou especialista na área materno-infantil, além de uma enfermeira } \\
\text { generalista para, posteriormente, preparar sua adequação nas habilitações existentes. (11.09.1980 - pg 10) }\end{array}$ \\
\hline
\end{tabular}

\author{
Madrigal da UFBA encerra Congresso de Enfermagem \\ do dia 2 passado, dirigem-se, em sua maioria, aos diretores de hospitais universitários, escolas de Enfermagem e à ABEn, sublinhando \\ a necessidade de currículo que possibilite ao aluno a percepção das características funcionais do exercício profissional. A par desse \\ educação para a profissão. (04.08.1975 - pg 3)
}

Valorizar a profissão, meta dos enfermeiros realidade; nem sempre as escolas têm recursos humanos e materiais disponíveis, que possibilitem uma aprendizagem mais objetiva". (04.05.1980 - pg 2) Encontro é encerrado com repúdio e sugestões

\title{
Enfermagem define hoje sua bandeira de luta
}

Os estudantes de Enfermagem defenderam que para que se viabilize a evolução desejada, tornam-se necessárias a introdução de melhores currículos, a realização de trabalhos comunitários vinculados ou não à universidade com maior valorização do processo de Enfermagem e, ainda, que se busque maior integração com os órgãos de classe. [...] "A nossa formação profissional não condiz com a realidade e nos leva a sermos submissos ao médico, inseguros e acomodados, preconceituosos em relação ao profissional do sexo masculino, burocratas pela sobrecarga do trabalho e distante do paciente. [...]". De acordo ainda com o relatório, o currículo dos cursos de Enfermagem não atende às necessidades do futuro profissional, "devido a uma indefinição do perfil profissional e a uma desvinculação entre a bagagem adquirida na escola e a realidade do trabalho desempenhada na comunidade". (25.07.1981 - pg 3)

\section{Enfermeira denuncia exploração da classe}

A enfermeira lembrou a importância e o papel social da Enfermeira, que "não deve ser esquecido pelos profissionais do setor, pois acrescentou - além de uma técnica, a Enfermagem é também uma prática social, mas como as faculdades sempre enfatizam a primeira, corremos o perigo de esquecer o seu papel social". (13.10.1981 - pg 3)

\section{Enfermagem luta pela valorização profissional}

Embora "nem hospitais, nem clínicas possam funcionar sem enfermeiros de nível superior", como acredita o Sindicato dos Profissionais de Enfermagem, Técnicos, Duchistas, Massagistas e Empregados em Hospitais e Casa de Saúde de Salvador, na Bahia, existe um déficit de auxiliares de enfermagem devidamente qualificados. O caminho que o Sindicato encontra para sanar tal deficiência é o mais correto possível: pedir à Secretaria da Educação do Estado que promova cursos para a formação destes profissionais. Tal orientação é passível de ser estendida a uma série de outras atividades auxiliares de profissionais e que hoje são exercidas por pessoas que são obrigadas a irem à Universidade e lá passar um mínimo de quatro anos para adquirir conhecimentos capazes de serem ministrados em muito menos tempo em escolas profissionalizantes de $2^{\circ}$ grau. (12.05.1980 - pg 1)

Enfermagem luta pela valorização profissional

Segundo Maria Ivete de Oliveira - que já foi secretária do Trabalho e Bem-Estar Social; no anteprojeto foi estabelecido um programa bem mais amplo de treinamento dos atendentes de enfermagem, estimulando-os a fazerem a suplência profissionalizante e, "se for o caso, provisionar os que tenham condições e interesse de melhorar a qualidade do trabalho". (12.05.1980 - pg 1)

\section{Enfermeira defende um novo modelo de saúde}

Sobre o assunto, os dados na Bahia não são animadores, pois a assistência de enfermagem é prestada, em sua maior parte, por profissionais não-habilitados, favorecendo a má qualidade do serviço prestado por causa da mão-de-obra mais barata. Os hospitais preferem contratar atendentes, que muitas vezes nem dispõem do primeiro grau de escolaridade e muito menos das noções sobre o atendimento direto a vidas humanas, do que enfermeiras especializadas. Por isso, o Conselho de Enfermagem está encampando uma luta no sentido de dar um preparo regular a esse pessoal, transformando-o em auxiliares de enfermagem. (15.07.1982 - pg 3)

FONTE: elaborada pelos autores. 
Quadro 1. Continuação...

\begin{tabular}{|c|c|}
\hline Recorte jornalístico & Tema \\
\hline Enfermagem: Felicidade maior é quando se dá um pouco de si & \multirow{10}{*}{$\begin{array}{l}\text { Qualificação } \\
\text { profissional }\end{array}$} \\
\hline $\begin{array}{l}\text { Na Bahia, a Semana de Enfermagem vai implantar um curso de extensão com } 27 \text { aulas, versando sobre a "Atualização em Enfermagem } \\
\text { Psiquiátrica Dinâmica", ministrado pelas professoras Stela Sena, da Universidade Federal da Bahia e Tereza Sena, Enfermeira Chefe do } \\
\text { Instituto de Psiquiatria do Rio de Janeiro. (17.05.1970 - pg 2) }\end{array}$ & \\
\hline Enfermagem luta pela valorizaçao profissional & \\
\hline $\begin{array}{l}\text { Com o acentuado número de indústrias funcionando na Bahia, a enfermagem do trabalho poderia ser de vital importância para a } \\
\text { prevenção de acidentes, mas o número de enfermeiros do trabalho é ínfimo [...] por isso, integrando a Semana de Enfermagem, } \\
\text { ocorrerá o I Encontro de Enfermagem do Trabalho [...] A partir desse encontro, que trará inclusive um representante do Ministério do } \\
\text { Trabalho à Bahia, poderá ser programado um curso de Enfermagem do Trabalho na Escola de Enfermagem da UFBA, para facilitar a } \\
\text { qualificação desses profissionais na área. (12.05.1980 - pg 1) }\end{array}$ & \\
\hline Enfermagem promoveu encontro estudantil & \\
\hline $\begin{array}{l}\text { [...] foi proferida palestra pela vice-presidenta do Conselho Regional de Enfermagem, professora Cirlene Pires, que abordou o tema } \\
\text { central do V Encontro [V Encontro Regional de Estudantes de Enfermagem do Nordeste] “O Perfil do Enfermeiro", seguido de um } \\
\text { extenso debate do qual tomou parte a quase totalidade dos congressistas. Ainda no mesmo dia, foi proferida palestra pela professora } \\
\text { Maristela Menezes Santos, da FEJ, sobre "Consciência na formação profissional” [...]. Dando continuidade [...], foram proferidos uma } \\
\text { palestra sobre "Absorção do Mercado de Trabalho", pela professora Cristina Melo, da UFBA, e no final um debate sob a coordenação da } \\
\text { professora Stella Barros sobre a "Atuação do Enfermeiro na realidade nordestina". (10.09.1985 - pg 10) }\end{array}$ & \\
\hline Debate marca o Dia Internacional da Mulher & \\
\hline $\begin{array}{l}\text { Comemorando o Dia Internacional da Mulher, acontece hoje um debate com o tema "Constituição Estadual, a Mulher e a Saúde", no } \\
\text { auditório da ABEn-BA, dando início à promoção Encontro Marcado. O Encontro Marcado terá uma programação sempre voltada para } \\
\text { a realidade e o momento atual, de interesse da categoria, que deverá agregar os profissionais em torno de questões fundamentais, a } \\
\text { serem discutidas ampla e democraticamente. A promoção da ABEn é parte da própria dinâmica da associação, empenhada em divulgar, } \\
\text { para o grande número de profissionais que a integram, as questões atuais, convocando-os à participação. (07.03.1989 - pg 2) }\end{array}$ & \\
\hline Dia Mundia da Saúde movimento enfermeiro & \\
\hline $\begin{array}{l}\text { À assembleia se seguirá o Encontro Marcado, no mesmo local, uma oportunidade de debate e conscientização da categoria e que } \\
\text { este mês estará a cargo do enfermeiro Jorge Lorenzetti, coordenador da Comissão de Legislação da ABEn-Nacional e professor da } \\
\text { Universidade Federal de Santa Catarina, que falará sobre "Lei Orgânica do Sistema Único de Saúde". (03.04.1989 - pg 4) }\end{array}$ & \\
\hline
\end{tabular}

FONTE: elaborada pelos autores.

modelos formativos em saúde, evidenciando a preocupação da categoria com o exercício consciente, comprometido com as necessidades de saúde e coerente com o contexto no qual estava inserido. A militância em prol do desenvolvimento da formação universitária resultou de um processo de autoavaliação das enfermeiras como profissionais e sujeitos sociais, que passaram a olhar para si, buscando reestruturar sua atuação conforme as demandas de saúde e concepções ideológicas emancipatórias.

No que diz respeito aos achados dos recortes jornalísticos categorizados como formação técnica, verifica-se a divulgação, pela mídia, da necessidade de qualificação de técnicos e auxiliares de Enfermagem diante do excessivo quantitativo de pessoal sem capacitação adequada exercendo atividades na área. No ano de 1985, a força de trabalho na Enfermagem era composta majoritariamente por atendentes de Enfermagem, profissionais sem qualificação adequada, que representavam $63,8 \%$ da categoria, seguidos de $21,1 \%$ de auxiliares de Enfermagem, $8,3 \%$ de enfermeiros e $6,8 \%$ de técnicos em Enfermagem ${ }^{24}$.

Denota-se que a força de trabalho expressa neste período era majoritariamente composta por pessoal com treinamento para as ações e cuidados básicos em Enfermagem, os atendentes de Enfermagem aqui indicados como sem qualificação formal e os demais profissionais de Enfermagem que compõem a categoria, composta por trabalhadores com processos formativos distintos, com diferenciação em nível de legislação, de exercício profissional e no que tange às perspectiva do mundo do trabalho, pois possuíam também diferenças salariais.

Diante da crise econômica, epidemias e consolidação da condução da Saúde Pública pelo Instituto Nacional de Previdência Social (INPS), houve uma grande demanda por profissionais de Enfermagem gerada pela expansão da rede de saúde, o que promoveu a criação dos cursos técnicos em Enfermagem ${ }^{25}$. Entretanto, a fragilidade em formar pessoal de nível técnico em quantidade suficiente, somada aos interesses capitalistas dos hospitais, que objetivavam o lucro em detrimento da qualidade do serviço ofertado, contribuiu para a condução da assistência de Enfermagem ao caos ${ }^{26}$.

No entanto, cabe ressaltar que essa dicotomia estabelecida entre a formação superior e os cursos de nível técnico nada mais foi do que a extensão de uma prática educacional implantada na 
década de 1930, que objetivava a qualificação profissional das camadas sociais de baixa renda para atender aos interesses do mercado de trabalho, ficando o nível superior reservado para as camadas sociais mais elitizadas ${ }^{27}$. A formação de pessoal técnico também atendia aos interesses de mercado, que intencionava baratear o custo da assistência em saúde e em Enfermagem. Essa dicotomia também reforçava a divisão social do trabalho e fragilizava politicamente a categoria, que passava a angariar conquistas individuais e não para o coletivo da equipe de Enfermagem.

Os resultados demonstram que a mídia destacou as denúncias realizadas pelas entidades de classe, principalmente pelo conselho, buscando conscientizar a população acerca dos interesses e riscos que permeavam a contratação de pessoal sem habilitação para exercer atividades no campo da Enfermagem.

Esse período coincidiu com a criação dos Conselhos Federal e Regionais de Enfermagem, viabilizados pelo interesse da ABEn em fundar um órgão responsável pela regulamentação profissional e fiscalização do ensino e da prática em Enfermagem ${ }^{28}$. As denúncias realizadas pelo conselho e noticiadas pelo jornal demonstravam o empenho do órgão em implementar um programa de profissionalização dos atendentes, motivado pela necessidade de controlar a expansão desordenada de pessoal sem qualificação formal que atuava na área e contribuía para a desvalorização da categoria, sobretudo das enfermeiras.

Como aponta a literatura ${ }^{29}$, a expansão de quantitativo heterogêneo de pessoal atuante na Enfermagem, excedendo a demanda necessária, resultou em um contingente de reserva de enfermeiras disputando entre si e com as demais trabalhadoras a inserção no mercado de trabalho. Consequentemente, a inexistência de concorrência entre os empregadores para a contratação de enfermeiras, somada à incipiente organização política da classe, principalmente no que diz respeito ao engajamento sindical, contribuiu para reduzir o valor do trabalho dessas profissionais.

Nessa perspectiva, coaduna-se com a autora ${ }^{29}$ ao argumentar que a divisão técnica e social do trabalho na Enfermagem implicou a desvalorização do trabalho das enfermeiras, visto que eram facilmente substituídas pelos empregadores por pessoal de nível médio. Tal divisão também coopera para a simplificação do trabalho dessa categoria e a perda da identidade e especificidade das profissões que integram a equipe de Enfermagem. Destacase que a fragmentação em funções simples anula, na prática, a diferença de atribuições entre enfermeiras e os demais praticantes da área de modo que a menos qualificada exerce a mesma função que outra, com formação superior. Já a divisão social do trabalho é representada como fonte de desigualdade social, pois, no desenvolvimento das atividades laborais, são reproduzidas as desigualdades de classe ${ }^{30}$.

A respeito da invisibilidade e desvalorização da especificidade do trabalho da enfermeira, ocasionadas pela fragmentação em diversas categorias, chama a atenção o posicionamento equivocado do Sindicato dos Profissionais de Enfermagem, Técnicos, Duchistas, Massagistas e Empregados em Hospitais e Casa de Saúde de Salvador, órgão representativo das categorias profissionais de saúde, que deveria ser responsável por atuar em defesa dos direitos trabalhistas. A referida entidade sindical subvalorizou a base científica teórica e prática da formação de enfermeiras, demonstrando incompreensão acerca do trabalho de cada integrante da equipe de Enfermagem. A entidade criticou a necessidade de sujeitar-se à formação universitária por período de quatro anos, alegando que tais conhecimentos seriam apreendidos em cursos profissionalizantes, como se isso fosse possível.

A propagação de representações irreais perpetua, no imaginário da sociedade, a invisibilidade da enfermeira e desqualifica a profissão, reduzindo sua atuação a práticas desprovidas de cientificidade. A ausência de limites de atuação claramente estabelecidos entre as profissionais deixava margem para a compreensão de que esse trabalho poderia ser exercido por qualquer outro trabalhador, mesmo sem qualificação formal.

Assim, diante desse contexto de precarização, fica evidente o interesse em controlar quem exercia a prática na área. A mobilização para a criação do conselho e a elaboração de propostas de profissionalização do pessoal de nível médio foram motivadas pelo interesse das enfermeiras em proteger a profissão na tentativa de preservar o status econômico e social de uma categoria de nível superior que detém conhecimento científico, competências e habilidades específicas não passíveis de serem apreendidos em cursos de menor duração.

A esse respeito, autores ${ }^{31}$ afirmaram que a aprovação da Lei $\mathrm{n}^{\circ} \mathbf{7 . 4 9 8 / 8 6}$, que regulamentou o exercício profissional em Enfermagem, também se constituiu em uma estratégia para qualificar os trabalhadores, pois regulamentou as quatro categorias que poderiam exercer atividades na área - enfermeiro, técnico de Enfermagem, auxiliar de Enfermagem e parteira -, definiu a função de cada integrante, impedindo que outros trabalhadores exercessem atribuições específicas das enfermeiras, e reconheceu a existência do atendente de Enfermagem, determinando sua extinção em até dez anos.

Em relação à última temática abordada nesta discussão, as reportagens trataram da divulgação da formação em Enfermagem ocorrida fora da estrutura formal do ensino de graduação e de nível médio. Como apontou um estudioso ${ }^{32}$, as relações pedagógicas de aprendizagem não se limitam ao ambiente escolar, pois ocorrem nos múltiplos espaços sociais e nas diversas relações estabelecidas entre os indivíduos.

Nesse sentido, os resultados noticiaram a atuação da ABEn na organização e divulgação de programações científicas como a Semana de Enfermagem e o projeto intitulado "Encontro Marcado" com o intuito de estabelecer espaços de discussão e debate sobre temas atuais na área da saúde, congregar a categoria ao redor de discussões sobre o ensino e a prática e divulgar informações de interesse da classe. Esses eventos eram promovidos pela ABEn, que buscava conscientizar a categoria acerca da necessidade de refletir sobre a profissão de forma crítica e coerente com o contexto sociopolítico no qual estava inserida. 
A participação de estudantes e trabalhadoras em espaços coletivos de discussão pode favorecer reflexões sobre a profissão, bem como a identificação de problemas e a elaboração de estratégicas voltadas para a melhoria e o desenvolvimento da Enfermagem. Evidências ${ }^{16}$ apontaram que a vivência em espaços que estimulam a reflexão, por meio de discussões críticas sobre a profissão, amplia a perspectiva de compreensão do indivíduo e incentiva o engajamento político, funcionando como catalisador para a militância profissional.

Além disso, a participação política e a atuação engajada são estimuladas por experiências formativas afastadas da Medicina e do modelo tecnicista praticado nas universidades. Conhecimentos interdisciplinares, de Saúde Coletiva, Sociologia e Administração, são pontuados como subsidiários para a formação militante e configuram-se como saberes libertários contra a invisibilidade, submissão e falta de identidade profissional ${ }^{17}$.

Nesse sentido, é elementar pontuar o posicionamento das estudantes de Enfermagem em busca de uma formação profissional imbuída de criticidade e engajada socialmente ${ }^{3,4}$, contemplando a dimensão política para além das esferas técnica e científica da formação. Os temas discutidos em encontros de estudantes de Enfermagem demonstraram a tomada de consciência que ocorria na década de 1980 por situarem a profissão no contexto real do mercado de trabalho, acometida por agruras e também conquistas, distante dos discursos idealizados e pautada em comportamentos devocionais.

Novamente, ressalta-se a importância da participação dos estudantes em espaços formativos que favoreçam o desenvolvimento de consciência política, visto que alunos que participaram ou atuaram em prol da profissão durante a sua formação tendem a ser politicamente ativos após tornarem-se profissionais.

O ensino em Enfermagem é historicamente modificável e suas transformações são também condicionadas às necessidades sociais e de mercado. Dessa forma, o modelo formativo deve ser constantemente reavaliado e modificado para atender não apenas aos interesses do mercado de trabalho, como também do corpo profissional.

\section{CONCLUSÕES E IMPLICAÇÕES PARA A PRÁTICA}

A militância profissional das enfermeiras no campo da formação foi evidenciada pela mídia por meio da atuação no contexto da formação universitária, comprometida com a formação técnica e em prol da qualificação profissional fora do contexto curricular da graduação.

No campo da formação universitária, as enfermeiras e estudantes de Enfermagem demonstraram posicionamento crítico e atuante em relação ao ensino descontextualizado praticado pelas universidades, pautado em metodologias ultrapassadas. Segundo elas, o aperfeiçoamento técnico era supervalorizado em detrimento da formação humanística social e havia frágil abordagem da dimensão política na formação, contribuindo para a prática profissional subjugada.
Em prol da formação técnica, a militância foi evidenciada a partir da luta empreendida pela qualificação dos trabalhadores de nível médio, tendo como principal motivador o empenho em assegurar as conquistas já alcançadas e coibir a desvalorização social e econômica do trabalho da enfermeira decorrente da fragmentação social e técnica do trabalho em Enfermagem. A fundação do Conselho de Enfermagem, como órgão fiscalizador e regulamentador da profissão, instrumentalizado também pelo aparato legal que normatizou o exercício da profissão, representou outra estratégia empreendida para melhorar a qualidade dos serviços prestados e combater a prática mercadológica de substituição de enfermeiros por outros trabalhadores não qualificados para esta função.

Já no âmbito da qualificação, verificou-se a atuação militante das instituições representativas, que se utilizaram da mídia para comunicar a necessidade de envolvimento em discussões ampliadas, coerentes com o contexto sociopolítico no qual a assistência se insere e comprometidas com os ideais de saúde e com o desenvolvimento e a valorização da profissão.

Por fim, destaca-se que este estudo teve como limitação alguns aspectos referentes à consistência do conteúdo apresentado nas reportagens, sendo esta uma particularidade característica de fontes jornalísticas. A falta de clareza e a explanação das ideias de forma demasiadamente sucinta demandaram maiores esforços para a compreensão das informações apresentadas nos recortes analisados.

Outra limitação está ligada à necessidade de recorte das fontes e da delimitação temporal do estudo. Apesar de não pretender generalizar os achados da pesquisa, é válido destacar a sua contribuição para a Enfermagem, pois, além de documentar os movimentos e as pautas da Enfermagem brasileira, o estudo aponta perspectivas estruturantes para a defesa da profissão, do campo de conhecimento e do cuidado em saúde e em Enfermagem.

\section{CONTRIBUIÇÕES DOS AUTORES}

Desenho do estudo. Aline Di Carla Laitano. Gilberto Tadeu Reis da Silva. Deybson Borba de Almeida. Victor Porfírio Ferreira Almeida Santos. Miller Fontes Brandão. Ridalva Dias Martins.

Aquisição de dados. Aline Di Carla Laitano. Gilberto Tadeu Reis da Silva. Deybson Borba de Almeida. Victor Porfírio Ferreira Almeida Santos. Miller Fontes Brandão. Ridalva Dias Martins.

Análise de dados e interpretação dos resultados. Aline Di Carla Laitano. Gilberto Tadeu Reis da Silva. Deybson Borba de Almeida. Victor Porfírio Ferreira Almeida Santos. Miller Fontes Brandão. Ridalva Dias Martins.

Redação e revisão crítica do manuscrito. Aline Di Carla Laitano. Gilberto Tadeu Reis da Silva. Deybson Borba de Almeida. Victor Porfírio Ferreira Almeida Santos. Miller Fontes Brandão. Ridalva Dias Martins.

Aprovação da versão final do artigo. Aline Di Carla Laitano. Gilberto Tadeu Reis da Silva. Deybson Borba de Almeida. Victor Porfírio Ferreira Almeida Santos. Miller Fontes Brandão. Ridalva Dias Martins. 
Responsabilidade por todos os aspectos do conteúdo e a integridade do artigo publicado. Aline Di Carla Laitano. Gilberto Tadeu Reis da Silva. Deybson Borba de Almeida. Victor Porfírio Ferreira Almeida Santos. Miller Fontes Brandão. Ridalva Dias Martins.

\section{EDITOR ASSOCIADO}

Antonio José Almeida Filho (D)

\section{EDITOR CIENTÍFICO}

\author{
Marcelle Miranda da Silva (iD)
}

\section{REFERÊNCIAS}

1. Almeida DB, Silva GTR, Freitas GF, Padilha MI, Almeida IFB. Discursive archaeology: constituting knowledge of militant nurses in trade associations. Rev Bras Enferm. 2018;71(3):1128-201. http://dx.doi. org/10.1590/0034-7167-2017-0277.

2. Collière MF. Promover a vida: da prática das mulheres de virtude aos cuidados de enfermagem. 5 ed. Lisboa: Lindel; 1999.

3. Chinn P. Critical theory and emancipatory knowing. In: Butts JB, Rich $\mathrm{KL}$, editors. Philosophies and theories for advanced nursing practice. Mississippi: Jones \& Bartlett Learning; 2015.

4. Cicchelli V. The Contemporary Engagement of young people in France: normative injunctions, institutional programas and the multiplying forms of grouping. Ital J Sociol Educ. 2009;1(2):104-27.

5. Pires CDO, Melo CMM. Gênese do movimento estudantil na Escola de Enfermagem da Universidade Federal da Bahia (1947-1959). Esc Anna Nery Rev Enferm. 2008;12(3):437-43. http://dx.doi.org/10.1590/ S1414-81452008000300007.

6. Almeida DB, Silva GTR, Freitas GF, Almeida IFB, Cunha ICKO, Amestoy SC. Freedom practices of nursing activists for the construction of other nursing objectification modalities. Rev Baiana Enferm. 2018;32:e25099. http://dx.doi.org/10.18471/rbe.v32.25099.

7. Silva AL, Padilha MICS, Borenstein MS. Imagem e identidade profissional na construção do conhecimento em enfermagem. Rev Latino-am Enferm. 2002;10(4):586-95. http://dx.doi.org/10.1590/S0104-11692002000400017.

8. Carvalho V. Sobre a Associação Brasileira de Enfermagem - 85 anos de história : pontuais avanços e conquistas, contribuições marcantes, e desafios. Rev Bras Enferm. 2012;65(2):207-14. http://dx.doi.org/10.1590/ S0034-71672012000200002.

9. Ghilardi-Lucena MI. Representações do gênero masculino na mídia impressa brasileira. 4으을 da Comunicação e da Informação" [Internet]; Porto; 2005. Porto: Universidade do Porto; 2005. p. 1018-25 [citado 2018 out 11]. Disponível em: http://www.bocc.ubi.pt/pag/ghilardi-maria-representacoes-generomasculino-midia-imprensa-brasileira.pdf

10. Botelho D. Sobre os meios e modos de fazer jornalismo na Primeira República: Lima Barreto entre a história e a ficção. Antíteses. 2013;6(11):3252. http://dx.doi.org/10.5433/1984-3356.2013v6n11p32.

11. Barros JD. O projeto de pesquisa em história: da escolha do tema ao quadro teórico. Petrópolis: Vozes; 2017.

12. Almeida Fo JC, Santos BO, Silva No AO. A historiografia brasileira: antes e depois de Capistrano de Abreu a Escola dos Annales. Encontro Internacional de Formação de Professores e Fórum Permanente de Inovação Educacional [Internet]; Aracaju; 2015. Aracaju: Unit; 2015. p. 1-11. (vol. 8, no. 1) [citado 2018 out 11]. Disponível em: https://eventos. set.edu.br/index.php/enfope/article/view/1556

13. Conselho Federal de Enfermagem. Enfermagem em números [Internet]. Salvador: COFEN; 2018 [citado 2018 nov 11]. Disponível em: http:// www.cofen.gov.br/enfermagem-em-numeros
14. Oliveira NL. História das diretoras da Escola de Enfermagem da Universidade Federal da Bahia (1946-1956) [dissertação]. Salvador: Universidade Federal da Bahia; 2016 [citado 2018 ago 25]. Disponível em: https://pgenf.ufba.br/sites/pgenf.ufba.br/files/7._dissertacao_nubia_lino. pdf

15. Almeida DB, Silva GTR, Queiros PJP, Freitas GF, Almeida IFB. Lúcia Esther Duque Moliterno: knowing the life story of a militant nurse. Rev Enferm UERJ. 2017;25:e13345. https://doi.org/10.12957/reuerj.2017.13345.

16. Almeida DB, Silva GTR, Queiros PJP, Freitas GF, Almeida IFB. Life story of Josicélia Dumêt Fernandes, teacher and nurse. Rev Enferm UERJ. 2017;25(1):1-5. http://dx.doi.org/10.12957/reuerj.2017.17105.

17. Almeida DB, Silva GTR, Freitas GF, Padilha MI, Almeida IFB. Arqueologia Discursiva: os saberes constitutivos de enfermeiras militantes. Investig Qual em Saúde [Internet]. 2017; [citado 2018 set 7];2:305-14. Disponível em: https://proceedings.ciaiq.org/index.php/ciaiq2017/ article/view/1221/1182

18. Miranda NM. Jornalistas em cena, artistas em pauta: análise da cobertura jornalística dos espetáculos teatrais baianos realizada pelos jornais $\mathrm{A}$ Tarde e Correio na década de 90 [dissertação]. Salvador: Universidade Federal da Bahia; 2001 [citado 2018 ago 29]. Disponível em: http://www. repositorio.ufba.br:8080/ri/bitstream/ri/9669/1/Nadja_dissertacaoseg. pdf

19. Mattos S. Como Jorge Calmon via o Jornalismo e o jornalista. Intercom Rev Bras Ciências da Comum. 2010;33(1):311-20. http://dx.doi. org/10.1590/rbcc.v33i1.159.

20. Franco MLPB. Análise de conteúdo. 4. ed. Brasília: Liber Livro Ltda; 2012.

21. Passos E. De anjos a mulheres 2. ed. Salvador: EDUFBA; 2012.

22. Fernandes JDC. Memorial da Escola de Enfermagem 1946-1996. Salvador: UFBA; 2001.

23. Alarcão I. Reflexão crítica sobre o pensamento de D. Schön e os programas de formação de professores. Rev Fac Educ. 1996;22:11-42. http://dx.doi.org/10.1590/S0102-25551996000200002.

24. Almeida MCP. A Formação do Enfermeiro Frente à Reforma Sanitária. Cad Saude Publica. 1986;2(4):505-10. http://dx.doi.org/10.1590/S0102311X1986000400010.

25. Bellaguarda MLR. Nexus e circunstâncias da história do Conselho Regional de Enfermagem em Santa Catarina (1975-1986) [tese]. Florianópolis: Universidade Federal de Santa Catarina; 2013 [citado 14 jul 2018]. Disponível em: https://repositorio.ufsc.br/bitstream/ handle/123456789/107000/320450. pdf?sequence=1\&isAllowed=y

26. Pava AM, Neves EB. A arte de ensinar enfermagem: uma história de sucesso. Rev Bras Enferm. 2011;64(1):145-51. http://dx.doi.org/10.1590/ S0034-71672011000100021.

27. Oliveira MCM, Lima TL, Baluta VH. A formação do profissional enfermeiro, no contexto das reformas de ensino no Brasil. Rev Grifos. 2014;3637:161-86. https://doi.org/10.22295/grifos.v23i36/37.2784.

28. Melo GA, Natividade AS, Nascimento RF. Conselhos de Enfermagem: criação e atribuições do sistema COFEN/COREN. Rev Científica FASETE [Internet]. 2015; [citado 2018 set 12]:260-73. Disponível em: https://www.unirios.edu.br/revistarios/media/revistas/2015/9/ conselhos_de_enfermagem.pdf

29. Santos TA. Valor da força de trabalho da enfermeira [dissertação]. Salvador: Universidade Federal da Bahia; 2012 [citado 24 maio 2018] Disponível em: https://repositorio.ufba.br/ri/bitstream/ri/16495/1/ Dissertação_Enf_Tatiane araújo dos Santos.pdf

30. Dutra HS. Social division of work and nursing. Rev Enferm UFPE on line. 2016;10(11):4161-3. http://dx.doi.org/10.5205/1981-8963v10i11a11503p4161-4163-2016.

31. Göttems LBD, Alves ED, Sena RR. Brazilian nursing and professionalization at technical level: a retrospective analysis. Rev Latino-am Enferm. 2007;15(5):1033-40. http://dx.doi.org/10.1590/S0104-11692007000500023.

32. Silveira RJT. Disciplina e liberdade no ensino: notas preliminares para a crítica ao espontaneísmo pedagógico a partir de Gramsci. EccoS. Rev Cient. 2017;0(44):289-305. http://dx.doi.org/10.5585/eccos. n44.7784. 